\title{
Quantum well intermixing for the fabrication of InGaAsN/GaAs lasers with pulsed anodic oxidation
}

\author{
Y. Qu, C. Y. Liu, and Shu Yuan ${ }^{\text {a) }}$ \\ School of Materials Engineering, Nanyang Technological University, Singapore 639798 \\ S. Z. Wang and S. F. Yoon \\ School of Electrical and Electronic Engineering, Nanyang Technological University, Singapore 639798 \\ Michael C. Y. Chan \\ Department of Electrical and Electronic Engineering, The University of Hong Kong, Hong Kong, \\ People's Republic of China \\ M. H. Hong \\ Data Storage Institute, Singapore 117608
}

(Received 18 August 2003; accepted 7 January 2004)

Quantum well (QW) intermixing was carried out by post-growth rapid thermal annealing in InGaAsN/GaAs QW laser structures grown by solid-source molecular-beam epitaxy. The intensity and width of the photoluminescence peak showed a dependence on annealing temperature and time, and the maximum intensity and minimum linewidth were obtained after the wafer was annealed at $670{ }^{\circ} \mathrm{C}$ for $60 \mathrm{~s}$. The peak luminescence energy blueshifted with increasing annealing time, although it plateaued at an annealing time that corresponded to that yielding the maximum luminescence intensity. The diffusion coefficient for indium was determined from a comparison between experimental data and modeling, but showed that QW intermixing alone was not sufficient to account for the relatively large blueshift after annealing. Defects related to the incorporation of nitrogen in the QW layer were responsible for the low photoluminescence efficiency in the as-grown samples and were annealed out during rapid thermal annealing. During annealing, nitrogen interstitials moved to vacancy sites within the QW and thus suppressed QW intermixing. After annealing wafers under conditions giving the maximum luminescence intensity, lasers were fabricated with pulsed anodic oxidation. (C) 2004 American Institute of Physics.

[DOI: $10.1063 / 1.1651322]$

\section{INTRODUCTION}

Semiconductor lasers emitting at a wavelength of 1.3 $\mu \mathrm{m}$ are highly desirable for fiber optic communications. Traditionally, such lasers are made of InGaAsP-based materials grown on InP wafers. Such lasers, however, are expensive and have poor high-temperature characteristics. Vertical cavity surface emitting lasers (VCSELs) are ideal for data communications at $1.3 \mu \mathrm{m}$; however, it is very difficult to fabricate VCSELs on InP substrates, due to the low refractive index contrast between InP-based materials. The InGaAsN/ GaAs material system grown on GaAs substrate, however, offers a potential solution to these problems. ${ }^{1-4}$ The addition of $\mathrm{N}$ to InGaAs/GaAs system reduces the compressive strain in the InGaAs layer, lowers the interband transition energies of InGaAs/GaAs quantum wells (QWs) and increases the conduction band offset, resulting in a longer emission wavelength (suitable for making $1.3 \mu \mathrm{m}$ lasers) and promising better high-temperature characteristics for $1.3 \mu \mathrm{m}$ laser diodes. ${ }^{5}$

Unfortunately, InGaAsN/GaAs lasers suffer from low luminescence efficiency due to nonradiative centers caused by the incorporation of N. ${ }^{6}$ Post-growth annealing reduces this

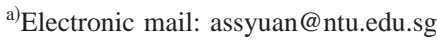

problem significantly, ${ }^{7}$ although the exact mechanism by which this is achieved is still debated. ${ }^{8-10}$ Spruytte et al. ${ }^{9}$ argued that defects associated with excess nitrogen in the material were responsible for the low luminescence efficiency, while Pan et al. ${ }^{7}$ proposed that interdiffusion of In-Ga and N-As was responsible for the improvement of material quality by using rapid thermal annealing (RTA) at low temperature $\left(\sim 650^{\circ} \mathrm{C}\right)$ and high temperature $\left(\sim 900^{\circ} \mathrm{C}\right)$, respectively. In comparison, Tournie et al. ${ }^{11}$ proposed that low growth temperature was responsible for the low radiative efficiency. In this work, we report a systematic study on QW intermixing (QWI) using RTA in InGaAsN/GaAs laser structures and obtain optimum RTA conditions for our laser structures in terms of luminescence intensity and peak width. We also include results from a laser fabricated using the optimum RTA conditions. Pulsed anodic oxidation ${ }^{12-14}$ is a simple method for the fabrication of semiconductor lasers. We have recently achieved a significant reduction of threshold current density in AlGaInP lasers by using this method. ${ }^{15}$ Pulsed anodic oxidation was used to form current blocking layers for the ridge waveguide InGaAsN lasers.

\section{EXPERIMENT}

The laser structures were grown by rf nitrogen plasmaassisted solid-source molecular-beam epitaxy (MBE). The 
TABLE I. Laser wafer structure used in this work. The QWI wafer used in the QW intermixing study had the same structure, except that the upper cladding layer was not grown.

\begin{tabular}{|c|c|c|c|}
\hline Layer & $\begin{array}{l}\text { Thickness } \\
\text { (nm) }\end{array}$ & $\begin{array}{l}\text { Doping } \\
\left(1 / \mathrm{cm}^{3}\right)\end{array}$ & $\begin{array}{c}\text { Growth } \\
\text { temperature } \\
\left({ }^{\circ} \mathrm{C}\right)\end{array}$ \\
\hline GaAs & 200 & Be $1 \times 10^{19}$ & 580 \\
\hline $\mathrm{Al}_{0.4} \mathrm{Ga}_{0.6} \mathrm{As}$ & 1500 & Be $5 \times 10^{17}$ & 610 \\
\hline GaAs & 150 & Undoped & 580 \\
\hline $\mathrm{In}_{0.32} \mathrm{Ga}_{0.68} \mathrm{As}_{0.983} \mathrm{~N}_{0.017}$ & 7 & Undoped QW & 460 \\
\hline GaAs & 40 & Undoped & 580 \\
\hline $\mathrm{In}_{0.32} \mathrm{Ga}_{0.68} \mathrm{As}_{0.983} \mathrm{~N}_{0.017}$ & 7 & Undoped QW & 460 \\
\hline GaAs & 40 & Undoped & 580 \\
\hline $\mathrm{In}_{0.32} \mathrm{Ga}_{0.68} \mathrm{As}_{0.983} \mathrm{~N}_{0.017}$ & 7 & Undoped QW & 460 \\
\hline GaAs & 150 & Undoped & 580 \\
\hline $\mathrm{Al}_{0.4} \mathrm{Ga}_{0.6} \mathrm{As}$ & 1500 & $\mathrm{Si}, 5 \times 10^{17}$ & 610 \\
\hline GaAs & 500 & $\mathrm{Si}, 1 \times 10^{18}$ & 580 \\
\hline (100) GaAs substrate & $400 \mu \mathrm{m}$ & $\mathrm{Si}, 1 \times 10^{18}$ & \\
\hline
\end{tabular}

growth chamber was equipped with standard effusion cell for arsenic and phosphorus, and the active nitrogen species were supplied by rf nitrogen plasma source. The samples were grown on (001) $n$-GaAs substrates that were Si-doped to a carrier concentration of $\sim 1 \times 10^{18} \mathrm{~cm}^{-3}$. Prior to the growth, surface oxide desorption was carried out under As flux at a beam equivalent pressure $(\mathrm{BEP})$ of $6.2 \times 10^{-6} \mathrm{~T}$. $(2 \times 4)$ surface reconstruction was maintained throughout the entire growth process. The BEPs for $\mathrm{Ga}$ and As were $4.5 \times 10^{-7}$ and $6.2 \times 10^{-6} \mathrm{~T}$, respectively. The As/Ga flux ratio was fixed at 14 . The growth rate was $\sim 1.0 \mu \mathrm{m} / \mathrm{h}$, verified by time-resolved reflection high-energy electron diffraction measurements. The nitrogen plasma source worked optimally at a nitrogen background pressure of $1.0 \times 10^{-5} \mathrm{~T}$ and at an arsenic $\mathrm{BEP}_{\mathrm{As}}$ of $6.2 \times 10^{-6} \mathrm{~T}$, and was activated by a rf power greater than $60 \mathrm{~W}$ to maintain the plasma in high brightness mode. Si and Be were used for $n$-type and $p$-type doping of the epitaxial layers, respectively. Two wafers were grown under the same conditions, one of which was used for the fabrication of the laser (termed "laser wafer"), the other for studying QWI (termed "QWI wafer"). The QWI wafer had the same structure as the laser wafer, except that the upper $p$-type cladding layer was not grown. The layer structures for these samples are listed in Table I. After the growth, the wafer was diced into small pieces of $3 \mathrm{~mm} \times 3 \mathrm{~mm}$. A thin $(\sim 200 \mathrm{~nm}) \mathrm{SiO}_{2}$ protection film was deposited on the samples prior to the annealing by electron-beam evaporation.

The samples were placed in the center area of a 4-in. Si wafer which was then loaded into the RTA chamber. The RTA chamber was purged with argon gas at $5 \mathrm{l} / \mathrm{min}$ for $5 \mathrm{~min}$ before the temperature was ramped up at a rate of $50{ }^{\circ} \mathrm{C} / \mathrm{s}$. After that, the gas flow was fixed at $2 \mathrm{l} / \mathrm{min}$ throughout the rest of the process. At high temperature, the temperature uniformity was within $\pm 5{ }^{\circ} \mathrm{C}$ across the whole 4-in. wafer. After RTA, photoluminescence (PL) measurements were performed at $77 \mathrm{~K}$ using an Ar ion laser beam (the $514.5 \mathrm{~nm}$ line), a spectrometer, and a thermal-electronically cooled InGaAs detector connected to a lock-in amplifier.

After RTA and PL measurements, the annealing conditions to maximize the luminescence intensity and minimize the width of the luminescence peak were identified and used in the fabrication of InGaAsN/GaAs/AlGaAs lasers. $50 \mu \mathrm{m}$ photoresist stripes were first made by standard photolithography, and the mesas were then etched in a solution of phosphoric acid, hydrogen peroxide, and deionized water. With the photoresist still on the ridges, pulsed anodization was performed to form the current blocking layer. The voltage pulse duration was $1 \mathrm{~ms}$, and the period was $12 \mathrm{~ms}$, and total anodization time was $6 \mathrm{~min}$. The wafer was thinned to $\sim 100$ $\mu \mathrm{m}$ thick and $\mathrm{Au} / \mathrm{Zn} / \mathrm{Au}$ and $\mathrm{Au}-\mathrm{Ge} / \mathrm{Ni}$ layers were deposited by electron-beam evaporation on the $p$-type and $n$-type sides, respectively, and annealed to make the ohmic contacts. Approximately $1200-\mu \mathrm{m}$ cavity length laser bars were then cleaved and individual lasers were sawed. The uncoated lasers were tested on a probe stage with junction side up.

\section{MODELING OF QWI}

In this work, the effects of RTA were experimentally characterized using PL measurements. The blueshift (i.e., shift towards higher photon energies) in PL peak energy results from the changes in the band structure after RTA. ${ }^{16}$ Pan et al. $^{7}$ proposed that at relatively low annealing temperatures $\left(\sim 650^{\circ} \mathrm{C}\right)$, In-Ga interdiffusion dominates, and at higher temperatures $\left(\sim 900^{\circ} \mathrm{C}\right) \mathrm{N}$-As interdiffusion becomes important. In this work, the maximum RTA temperature was $680^{\circ} \mathrm{C}$, so only In-Ga interdiffusion was taken into account in the modeling. Due to In and Ga interdiffusion, the QW shape changes from square to a smoothed one, which is usually described by the error function. This changes the electron and hole subband energies, and therefore changes (blueshifts) the PL energy. Therefore, a calculation of the interband transition energy that takes into account the change in strain in the QW and the changes in carrier confinement profiles due to $\mathrm{Ga}$ and In interdiffusion will yield the diffusion coefficients and will shed light on the complex interdiffusion processes.

The extent of the interdiffusion process is generally characterized by a diffusion length $L_{d}$, defined here as $L_{d}$ $=\sqrt{D t}$, where $D$ is the interdiffusion coefficient for indium and $t$ is the annealing time. We assumed an isotropic interdiffusion of In and Ga with the diffusion coefficients being independent of their respective concentrations, which were also assumed to be equal and constant; that is, Fick's second law of diffusion applies. The diffused In composition profile $w(z)$ across the $\mathrm{QW}$ structure is given by

$$
w(z)=\frac{w_{o}}{2}\left[\operatorname{erf}\left(\frac{L_{z}+2 z}{4 L_{d}}\right)+\operatorname{erf}\left(\frac{L_{z}-2 z}{4 L_{d}}\right)\right],
$$

where $w_{o}$ is the as-grown In mole fraction in the well, $L_{z}$ is the as-grown width of the $\mathrm{QW}$, and $z$ is the coordinate along the growth direction ( $\mathrm{QW}$ is centered at $z=0)$. Further details of the modeling are described elsewhere. ${ }^{17-21}$

The calculated QW interband transition energies were fitted to the measured PL peak energies by adjusting the value of $D$, thus $D$ was determined. 


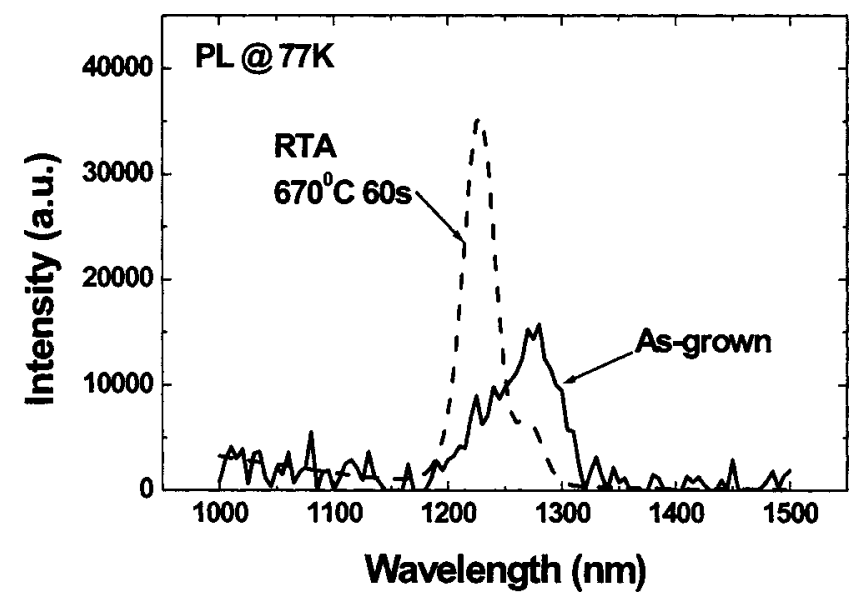

FIG. 1. Typical PL spectra from as-grown QWI wafer and QWI wafer annealed at $670{ }^{\circ} \mathrm{C}$ for $60 \mathrm{~s}$.

\section{PL MEASUREMENTS}

To study the effects of RTA on the QW intermixing in InGaAsN/GaAs samples and to find the optimum conditions for luminescent efficiency, we measured PL spectra at $77 \mathrm{~K}$ for as-grown and annealed samples. Figure 1 shows typical spectra for a piece of QWI wafer (as-grown) and a piece of QWI wafer annealed at $670{ }^{\circ} \mathrm{C}$ for $60 \mathrm{~s}$. After annealing, the PL intensity increased significantly, and the linewidth also narrowed, indicating an increase in the radiation efficiency. It has been proposed that the incorporation of nitrogen into InGaAs layer introduces nonradiative centers (crystal defects or impurities). ${ }^{9}$ Annealing reduced the nonradiative center density. The photon energy was also shifted to shorter wavelength.

Figure 2 shows the PL intensity from the QWI wafer as a function of annealing time for four different RTA temperatures between 630 and $680^{\circ} \mathrm{C}$. The PL intensity was taken as the integrated area under the peak. The overall trend is that optimized intensity can be found under conditions between 650 and $680^{\circ} \mathrm{C}$ for around $60 \mathrm{~s}$. Pan et al. ${ }^{7}$ annealed their MBE-grown InGaAsN/GaAs QWs at $650{ }^{\circ} \mathrm{C}$ for durations up

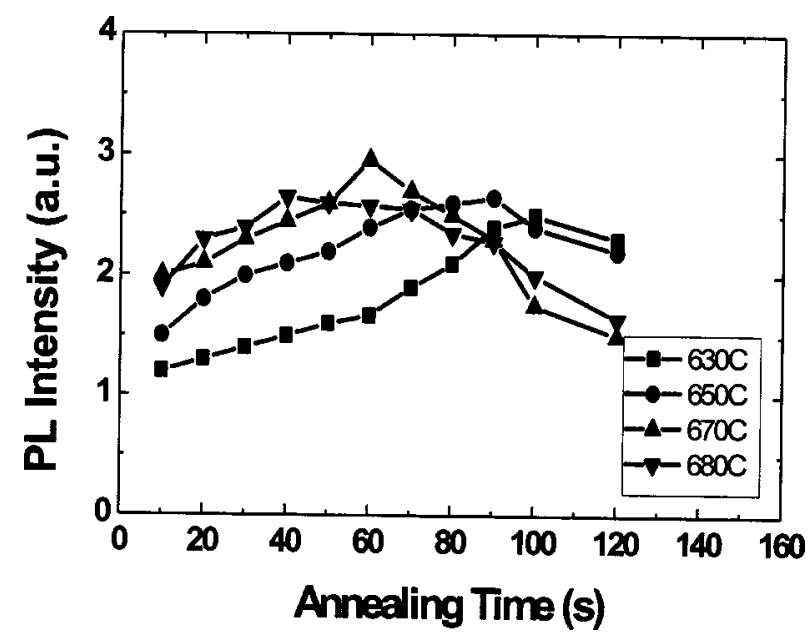

FIG. 2. PL intensity from the QWI wafer as a function of annealing time for different RTA temperatures.

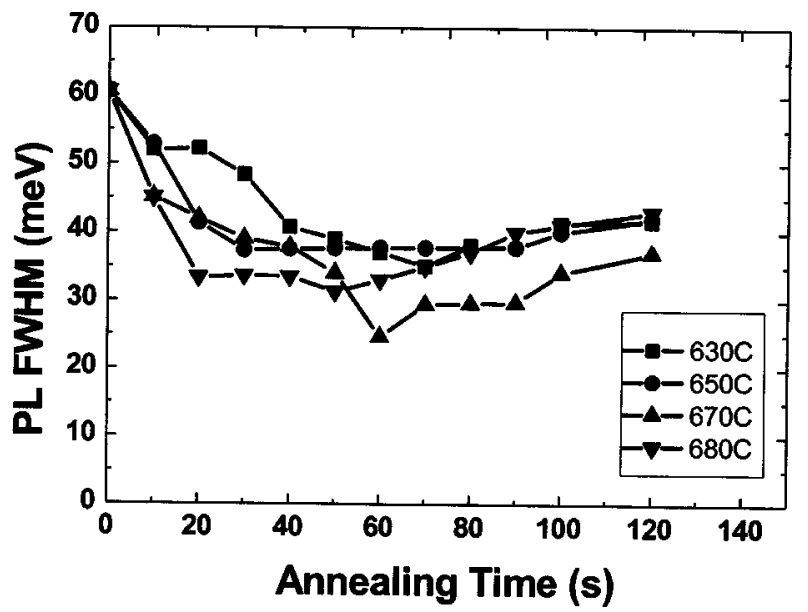

FIG. 3. PL linewidth (FWHM) from the QWI wafer as a function of annealing time for different RTA temperatures.

to $30 \mathrm{~min}$ (much longer than our $60 \mathrm{~s}$ ), and observed that RTA generally improved the PL intensity, with intensity increasing with annealing time. They also found that for InGaAs/GaAs QW samples the PL intensity was insensitive to RTA annealing. They annealed samples at $900^{\circ} \mathrm{C}$, and found that PL intensity reached the maximum after $5 \mathrm{~s}$ annealing, and then dropped with annealing time for both InGaAs/GaAs and InGaAsN/GaAs samples. Kageyama et al. ${ }^{10}$ annealed InGaAsN/GaAs QWs grown by chemicalbeam epitaxy at a fixed duration of $30 \mathrm{~s}$ and found that maximum PL intensity was obtained at $675^{\circ} \mathrm{C}$. While Kageyama's InGaAsN QW had only $0.7 \% \mathrm{~N}$, noticeably lower than $1.7 \% \mathrm{~N}$ in our laser structure, and their samples were grown not by MBE, nevertheless, their optimum temperature was essentially the same as ours, and their optimum RTA duration was shorter than demonstrated in this study (30 $\mathrm{s}$ versus $60 \mathrm{~s}$ ). Xin et al. ${ }^{5}$ however, found that the maximum PL intensity was achieved with an anneal temperature of about $850^{\circ} \mathrm{C}$ for $\mathrm{InGaAsN} / \mathrm{GaAs}$ QWs, much higher than our optimum temperature of about $670{ }^{\circ} \mathrm{C}$.

PL linewidth as measured by full width at halfmaximum (FWHM) is also an important parameter for studying the luminescence efficiency. Figure 3 shows FWHM as a function of RTA time for different temperatures. For all annealing temperatures, it reaches a minimum for a duration of around $60 \mathrm{~s}$. The smallest peak width of $25 \mathrm{meV}$ was measured after annealing at $670{ }^{\circ} \mathrm{C}$ for $60 \mathrm{~s}$, conditions which also yielded the highest PL intensity as shown in Fig. 2.

The PL photon energy also shifted towards higher energies with annealing time, as shown in Fig. 4. For all the temperatures, the blueshift was larger than $20 \mathrm{meV}$ even when annealing for as little as $10 \mathrm{~s}$. Yuan et al. ${ }^{12}$ recently reported RTA annealing of InGaAs/GaAs QW samples at $825^{\circ} \mathrm{C}$ for $30 \mathrm{~s}$ and observed negligible blueshift. The relatively large blueshift in this work might be due to (1) the effect of the $\mathrm{SiO}_{2}$ encapsulation, which was deposited onto the sample before RTA, and (2) the incorporation of nitrogen into InGaAs layers. $\mathrm{SiO}_{2}$ is well know to enhance QW intermixing in InGaAs/GaAs ${ }^{22}$ and GaAs/AlGaAs ${ }^{23}$ QWs be- 


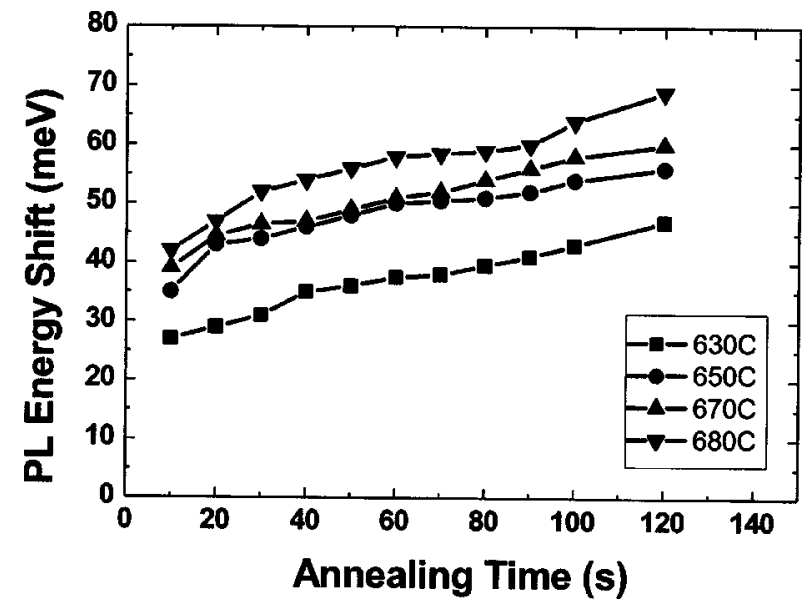

FIG. 4. PL photon energy shift with respect to the peak photon energy of the as-grown sample as a function of annealing time for different RTA temperatures.

cause of the large diffusion coefficient of $\mathrm{Ga}$ in $\mathrm{SiO}_{2}$, which increases $\mathrm{Ga}$ vacancies in GaAs and in turn enhances $\mathrm{Ga}$ and In interdiffusion. Similar effects have also been observed in GaNAs/GaAs QWs. ${ }^{24}$ Burker et al. $^{22}$ did RTA in InGaAs/ GaAs QWs capped with $\mathrm{SiO}_{2}$ at temperatures higher than $850^{\circ} \mathrm{C}$. From their results, we estimate a diffusion coefficient value of about $5 \times 10^{-17} \mathrm{~cm}^{2} / \mathrm{s}$ at $700{ }^{\circ} \mathrm{C}$ for $15 \mathrm{~s}$. In this work, a diffusion coefficient value of $3.4 \times 10^{-16} \mathrm{~cm}^{2} / \mathrm{s}$ for the annealing at $680^{\circ} \mathrm{C}$ for $20 \mathrm{~s}$ has been determined, which is much higher than the above estimation from Ref. 22. Thus, the $\mathrm{SiO}_{2}$ cap alone does not account for the large blueshift observed in this work.

It is possible that the incorporation of nitrogen into InGaAs/GaAs QW also enhances the interdiffusion of In and Ga atoms. Since QW intermixing is usually enhanced by an increase in the number of group-III vacancies, it is possible that the incorporation of nitrogen into InGaAs QW layer generated group-III vacancies (in addition to producing nitrogen interstitials). The blueshift increased with RTA time from 0 to about $50 \mathrm{~s}$, then remained constant at around $60 \mathrm{~s}$, and after about $80 \mathrm{~s}$, it started to increase again. The blueshift is an indication of atom interdiffusion (e.g., In and Ga interdiffusion) in the QW, which is often enhanced by increasing group-III vacancy density. ${ }^{21}$ The plateauing of the blueshift at around $60 \mathrm{~s}$ in Fig. 4 coincides with the maximum PL intensity in Fig. 2, indicating a minimization in vacancy density by RTA under those conditions. Spruytte et $a{ }^{9}{ }^{9}$ found that as-grown samples contained a significant concentration of interstitial nitrogen that disappeared following a 1 min anneal at $760{ }^{\circ} \mathrm{C}$. It is well known that if the vacancies in the sample are occupied by other atoms the number of vacancies is reduced and atomic interdiffusion can be suppressed. For example, in Ref. 25, $\mathrm{Zn}$ diffused from p-type GaAs substrate into GaAs/AlGaAs QWs, occupying vacancy sites within the $\mathrm{QW}$, suppressing the $\mathrm{Ga}-\mathrm{Al}$ atomic interdiffusion, and reducing the blueshift in the PL spectra. ${ }^{25}$ If interstitial nitrogen atoms in our samples had moved to occupy some of the vacancies during the annealing, especially under the "optimum" RTA conditions (i.e., $670{ }^{\circ} \mathrm{C}$ for $60 \mathrm{~s})$, the QW intermixing could be suppressed, resulting in

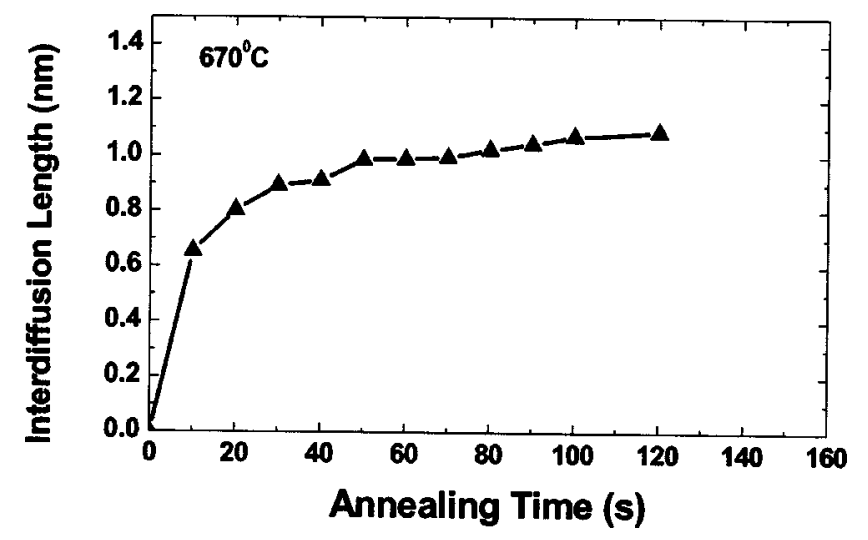

FIG. 5. Diffusion length versus annealing time for QWI wafer samples annealed at $670^{\circ} \mathrm{C}$.

the plateauing of the PL blueshift, as shown in Fig. 4. It is possible that the reduction in the number of vacancies and nitrogen interstitials reduced the scattering of photongenerated carries in the PL measurement, leading to the reduction of the PL line width shown in Fig. 3.

The diffusion length was determined as outlined in Sec. III, and is shown as a function of RTA time in Fig. 5 for RTA temperature of $670{ }^{\circ} \mathrm{C}$.

\section{InGaAsN/GaAs LASERS FABRICATED WITH PULSED ANODIC OXIDATION}

The laser wafer was annealed at $670{ }^{\circ} \mathrm{C}$ for $60 \mathrm{~s}$ (the annealing conditions that yielded the maximum PL intensity), then processed into lasers using the pulsed anodic oxidation method. The lasers were tested in $\mathrm{cw}$ mode at $18 \mathrm{~K}$, and the optical and electrical characteristics are shown in Fig. 6. Lasing was observed at currents above $250 \mathrm{~mA}$. The laser from this material shows a total slope efficiency at $T$ $=18 \mathrm{~K}$ of $16 \mathrm{~mW} / 50 \mathrm{~mA}=0.32 \mathrm{~W} / \mathrm{A}$. As a comparison, values around $0.48 \mathrm{~W} / \mathrm{A}$ were routinely obtained from InGaAsP laser at room temperature. ${ }^{26}$ Due to the relatively poor quality of the wafer, no lasers were fabricated from wafers that

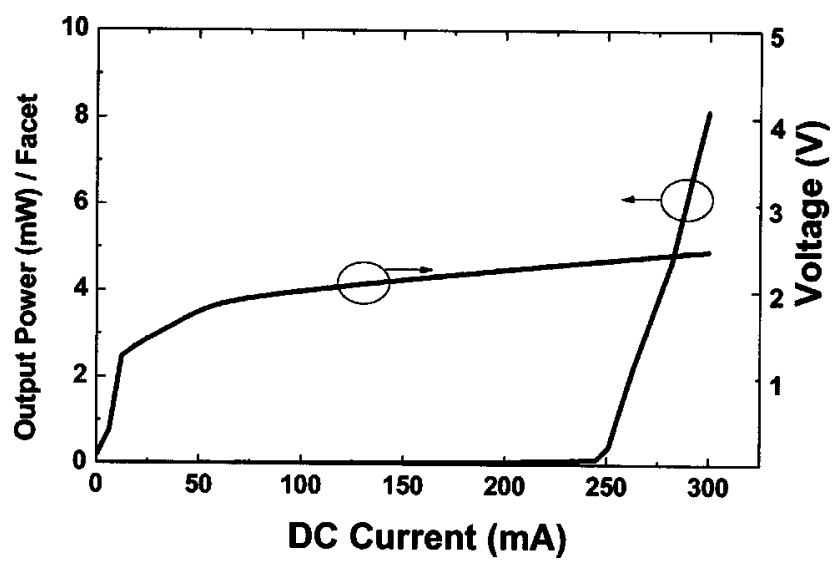

FIG. 6. Light output power of per facet versus current $(L-I)$ and voltage versus current $(V-I)$ characteristics at $18 \mathrm{~K}$ for a $50 \mu \mathrm{m} \times 1200 \mu \mathrm{m}$ laser diode that was annealed at $670{ }^{\circ} \mathrm{C}$ for $60 \mathrm{~s}$ and fabricated with pulsed anodic oxidation. 


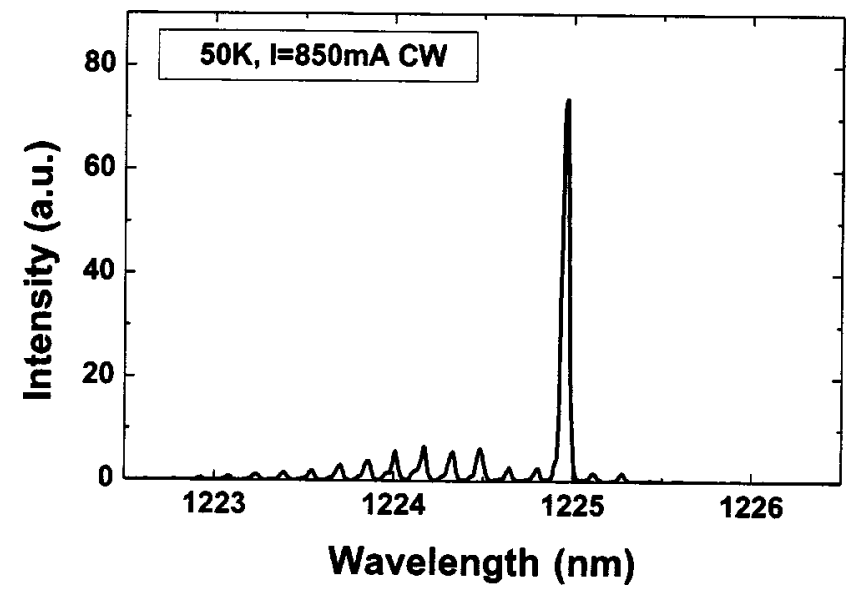

FIG. 7. Emission spectrum at $50 \mathrm{~K}$ for the same laser diode characterized in Fig. 6.

were annealed under other conditions. Work is in progress to grow higher quality wafers. Figure 7 shows a typical laser emission spectrum at $50 \mathrm{~K}$.

\section{CONCLUSIONS}

In this work, two InGaAsN/GaAs structures were grown by solid-source MBE. One was a laser structure, and the other was the same except that the upper cladding layer was not grown. RTA was carried out at temperatures from 630 to $680^{\circ} \mathrm{C}$ and QW intermixing-was observed. Maximum PL intensity and minimum linewidth at half-maximum were obtained after annealing at $670{ }^{\circ} \mathrm{C}$ for $60 \mathrm{~s}$. The PL photon energy blueshifted annealing time, but it plateaued under the annealing conditions, yielding the maximum luminescence intensity. Determining the diffusion coefficient from a comparison between experimental data and modeling showed that QW intermixing alone was not sufficient to account for the relatively large blueshift measured after annealing. Defects related to the incorporation of nitrogen in the QW layer were responsible for the low PL efficiency in as-grown samples and were annealed out during RTA. During the annealing, nitrogen interstitials moved to take up some vacancy sites in the QW and thus suppressed QW intermixing. Lasers were fabricated with pulsed anodic oxidation after annealing under optimized conditions.

\section{ACKNOWLEDGMENTS}

We appreciate Dr. A. Dowd for carefully reading the manuscript and for giving many good suggestions. One au- thor (Y. Q.) acknowledges financial support from Data Storage Institute of Singapore under a DSI-NTU joint project. We thank Dr. B. X. Bo and Dr. X. H. Tang for help in the PL measurement.

${ }^{1}$ W. Ha, V. Gambin, M. Wistey, S. Bank, S. Kim, and J. S. Harris, Jr., IEEE Photonics Technol. Lett. 14, 591 (2002).

${ }^{2}$ N. Tansu, A. Quandt, M. Kanskar, W. Mulhearn, and L. J. Mawst, Appl. Phys. Lett. 83, 18 (2003).

${ }^{3}$ C. S. Peng, T. Jouhti, P. Laukkanen, E. M. Pavelescu, J. Konttinen, W. Li, and M. Pessa, IEEE Photonics Technol. Lett. 14, 275 (2002).

${ }^{4}$ O. Malis, W. K. Liu, C. Gmachl, J. M. Fastenau, A. Joel, P. Gong, S. W. Bland, and N. Moshegov, J. Cryst. Growth 251, 432 (2003).

${ }^{5}$ H. P. Xin, K. L. Kavanagh, M. Kondow, and C. W. Tu, J. Cryst. Growth 201/202, 419 (1999).

${ }^{6}$ T. K. Ng, S. F. Yoon, S. Z. Wang, W. K. Loke, and W. J. Fan, J. Vac. Sci. Technol. B 20, 964 (2002).

${ }^{7}$ Z. Pan, L. H. Li, W. Zhang, Y. W. Lin, R. H. Wu, and W. Ge, Appl. Phys. Lett. 77, 1280 (2000).

${ }^{8}$ S. Z. Wang, S. F. Yoon, W. K. Loke, C. Y. Liu, and S. Yuan, J. Cryst. Growth 255, 258(2003).

${ }^{9}$ S. G. Spruytte, C. W. Coldren, J. S. Harris, Jr., W. Wampler, P. Krispin, K. Ploog, and M. C. Larson, J. Appl. Phys. 89, 4401 (2001).

${ }^{10}$ T. Kageyama, T. Miyamoto, S. Makino, F. Koyama, and K. Iga, Jpn. J. Appl. Phys. 38, L298 (1999).

${ }^{11}$ E. Tournie, M. A. Pinault, and A. Guzman, Appl. Phys. Lett. 80, 4148 (2002)

${ }^{12}$ S. Yuan, C. Y. Liu, F. Zhao, M. C. Y. Chan, W. K. Tsui, L. V. Dao, and X. Q. Liu, J. Appl. Phys. 93, 9823 (2003).

${ }^{13}$ S. Yuan, C. Jagadish, Y. Kim, Y. Chang, H. H. Tan, R. M. Cohen, M. Petravic, L. V. Dao, M. Gal, M. C. Y. Chan, E. H. Li, and P. S. Zory, IEEE J. Sel. Top. Quantum Electron. 4, 629 (1998).

${ }^{14}$ M. J. Grove, D. A. Hudson, P. S. Zory, R. J. Dalby, C. M. Harding, and A. Rosenberg, J. Appl. Phys. 76, 587 (1994).

${ }^{15}$ C. Y. Liu, Shu Yuan, J. R. Dong, S. J. Chua, M. C. Y. Chan, and S. Z. Wang, J. Appl. Phys. 94, 2962 (2003).

${ }^{16}$ S. Yuan, Y. Kim, C. Jagadish, P. T. Burke, M. Gal, J. Zou, D. Q. Cai, D. J. H. Cockayne, and R. M. Cohen, Appl. Phys. Lett. 70, 1269 (1997).

${ }^{17}$ M. C. Y. Chan, C. Surya, and P. K. A. Wai, J. Appl. Phys. 90, 197 (2001).

${ }^{18}$ D. Ahn and S. L. Chuang, IEEE J. Quantum Electron. 24, 2400 (1988).

${ }^{19}$ S. L. Chuang, Phys. Rev. B 43, 9649 (1991).

${ }^{20}$ D. J. BenDaniel and C. B. Duke, Phys. Rev. 152, 683 (1966).

${ }^{21}$ S. Yuan, Y. Kim, C. Jagadish, P. T. Burke, M. Gal, M. C. Y. Chan, E. H. Li, and R. M. Cohen, J. Appl. Phys. 83, 1305 (1998).

${ }^{22}$ S. Burkner, M. Baeumler, J. Wagner, E. C. Larkins, W. Rothemund, and J. D. Ralston, J. Appl. Phys. 79, 6818 (1996).

${ }^{23}$ B. S. Ooi, S. G. Ayling, A. C. Bryce, and J. H. Marsh, IEEE Photonics Technol. Lett. 7, 944 (1995).

${ }^{24}$ L. H. Li, Z. Pan, Y. Q. Xu, Y. Du, Y. W. Lin, and R. H. Wu, Appl. Phys. Lett. 78, 2488 (2001).

${ }^{25}$ F. Zhao, I. W. Choi, S. Yuan, C. Y. Liu, J. Jiang, and M. Chan, Thin Solid Films 426, 186 (2003).

${ }^{26}$ D. A. Ackerman, G. E. Shtengel, M. S. Hybertsn, P. A. Morton, R. F. Kazarinov, T. Tanbun-Ek, and R. A. Logan, IEEE J. Sel. Top. Quantum Electron. 1, 250 (1995). 